\title{
Non-occupational pneumoconiosis at high altitude villages in central Ladakh
}

\author{
H N Saiyed, Y K Sharma, H G Sadhu, T Norboo, P D Patel, T S Patel, K Venkaiah, \\ S K Kashyap
}

\begin{abstract}
An epidemiological survey was carried out to investigate the occurrence of nonoccupational pneumoconiosis in Ladakh, where there are no mines or industries. The clinicoradiological investigations of 449 randomly selected subjects from three villages showed typical cases of pneumoconiosis associated with progressive massive fibrosis and egg shell calcification of hilar glands. The prevalence of pneumoconiosis in these three villages was $2 \cdot 0 \%, 20 \cdot 1 \%$ and $45 \cdot 3 \%$ and it corresponded with the severity of dust storms and the use of chimneys in the kitchens. The dust concentrations in the kitchens with no provision for a chimney were very high. The free silica content of the storms was between $\mathbf{6 0}$ and $70 \%$. Exposure to free silica from dust storms and soot from domestic fuels are suggested as causes of these cases of pneumoconiosis.
\end{abstract}

Ladakh is among the highest of the world's inhabited plateaux. Leh, the headquarters of Ladakh is situated at a height of about 11000 feet in the western Himalayas. High altitude is responsible for severe and long winters and low barometric pressure (about $500 \mathrm{~mm} \mathrm{Hg}$ ). During winter, the temperatures are subzero (often between $-20^{\circ} \mathrm{C}$ and $-30^{\circ} \mathrm{C}$ ) and can approach zero during the rest of the year. Due to scanty rainfall (about 2 to 3 inches a year) the area is arid desert.

National Institute of Occupational Health, Meghani Nagar, Ahmedabad-380016, India

HN Saiyed, Y K Sharma, H G Sadhu, P D Patel, T S Patel, K Venkaiah, S K Kashyap

Regional Occupational Health Centre (Eastern), 3 Dr M Ishaque Road (Kyd Street), Calcutta-700016, India

H N Saiyed

SNM Hospital, Leh (Ladakh), India

T Norboo
This study was undertaken to investigate cases of respiratory morbidity seen at SNM hospital, Leh, who did not respond to routine treatment and whose radiological picture resembled pneumoconiosis. There are no mines or industries in any part of Ladakh and therefore exposure to dust from these sources is ruled out. Two factors considered responsible for the development of this respiratory morbidity were: (1) Exposure to dust from "dust storms." In spring dust storms occur in most parts of Ladakh. During these storms the affected villages are covered by a thick blanket of fine dust, and inhabitants are exposed to considerable amounts of the dust for several days. The frequency, duration, and severity of these dust storms vary considerably from one village to another. (2) Exposure to soot. The fuels used for heating and cooking consist of wood from a local bush called "malchung" and the dung of yaks, cows, horses, donkeys, and their interbreeds. Due to severe cold, the ventilation in the houses is usually kept at a minimum. The same fireplace is used for cooking and heating purposes. To conserve fuel during non-cooking periods, the wood is not allowed to burn quickly but is kept smouldering to prolong its slow heating effect. The dwellers are thus exposed to high concentrations of soot.

Materials and methods

Three villages, Saboo (A), Shey (B), and Chushot (C), situated near Leh town, were selected for the study. The characteristics of these villages are as follows: dust storms are rare in village $A$, moderate in village $B$, and severe in village $C$. Chimneys have been used for over 20 years in all houses in village $A$, for 10-20 years in most houses in village $B$, and in few houses and only recently in village $C$.

The total populations of villages $A, B$, and $C$ were 1045,1136 , and 924 respectively. As most of the cases of pneumoconiosis seen in the hospital were older than 50 , only those subjects older than 30 were included in this study. Initially, a list of all villagers older than 30 was prepared and from this list 150 subjects from each village were selected for the study. The list showed that in village $A$ and village $B$ there were more women than men, whereas in village $C$ this 
Table 1 Sex and age of subjects selected for the study

\begin{tabular}{llll}
\hline & Village & & \\
\cline { 2 - 4 } & $A(n=150)$ & $B(n=149)$ & $C(n=150)$ \\
\hline Women: & $82(54 \cdot 6)$ & $95(63 \cdot 8)$ & $68(45 \cdot 3)$ \\
No(\%) & $47 \cdot 95(11 \cdot 9)$ & $47 \cdot 24(12 \cdot 1)$ & $40 \cdot 68(8 \cdot 5)$ \\
Age (mean (SD)) & $68(45 \cdot 3)$ & $54(36 \cdot 2)$ & $82(54 \cdot 6)$ \\
Men: (\%) & $53 \cdot 56(13 \cdot 8)$ & $51 \cdot 20(14 \cdot 6)$ & $49 \cdot 1(12 \cdot 3)$ \\
Age (mean (SD)) & & & \\
\hline
\end{tabular}

Table 2 Prevalence of respiratory symptoms among the Ladakhi villagers

\begin{tabular}{|c|c|c|c|}
\hline & \multicolumn{3}{|l|}{ Village } \\
\hline & $A(n=150)$ & $B(n=149)$ & $C(n=150)$ \\
\hline $\begin{array}{l}\text { Cough and sputum }(\mathrm{No}(\%)) \\
\text { Dyspnoea }(\mathrm{No}(\%)) \\
\text { Symptomatic subjects }(\mathrm{No}(\%))\end{array}$ & $\begin{array}{l}34(22 \cdot 7) \\
29(19 \cdot 3) \\
36(24 \cdot 0)\end{array}$ & $\begin{array}{l}62(41 \cdot 6) \\
52(34 \cdot 9) \\
68(45 \cdot 6)^{\star \star}\end{array}$ & $\begin{array}{l}69(46 \cdot 0) \\
56(37 \cdot 3) \\
74(49 \cdot 3) \star \star\end{array}$ \\
\hline
\end{tabular}

$\star \star p<0.01$ compared with $A$.

was reversed. None of the selected subjects had ever worked in mines or industries.

The subjects underwent medical examination as per precoded form, pulmonary function tests, and electrocardiography, and chest $x$ ray films were taken on a $300 \mathrm{~mA} x$ ray machine. The chest $x$ ray films were read by three of us (HNS, YKS, and SRK) who are experienced readers using the guidelines and standard films provided by the International Labour Organisation. ${ }^{1}$

The environmental study consisted of the collection of indoor air samples from the residences and from the outdoor ambient environment of the villages using a traditional cone sampler and an Anderson size selecting sampler. The dust samples were analysed by infrared spectrophotometry. ${ }^{2}$ In the present communication, the radiological findings and the results of the environmental study are reported.

\section{Results}

Table 1 shows the sex distribution and age of the study subjects. More female subjects were included in the study from villages $A$ and $B$. This is because of the higher proportion of women in these villages. The mean age of men was greater than that of women

Table 3 Distribution of pneumoconiosis (ILO 1980) cases in 449 villagers from central Ladakh

\begin{tabular}{lr}
\hline No of subjects radiographed & \\
Subjects showing pneumoconiosis & 449 \\
Category 1 & $101(22 \cdot 5)$ \\
Category 2 & $53(52 \cdot 5)$ \\
Category 3 & $37(36 \cdot 5)$ \\
Categories A, B, and C & $1(1 \cdot 0)$ \\
\hline
\end{tabular}

Figures in parentheses are percentages. in all the villages. The principal occupation of the subjects is farming.

Table 2 shows the prevalence of respiratory symptoms in the study subjects. It was significantly higher in village $B$ and village $C$ compared with village $A$. The major respiratory symptoms were cough, sputum production, and dyspnoea.

Table 3 shows radiological findings for the study population. A total of $101(22.5 \%)$ subjects showed radiological evidence of pneumoconiosis. Out of these, $91(90 \cdot 1 \%)$ subjects showed small opacities (maximum diameter less than $10 \mathrm{~mm}$ ) and $10(9.9 \%$ ) subjects showed large opacities (maximum diameter equal to or greater than $10 \mathrm{~mm}$ ). These small and large opacities are frequently referred to as "simple pneumoconiosis" and "complicated pneumoconiosis" or "progressive massive fibrosis" respectively. ${ }^{3}$ The profusion distribution of small opacities in categories 1,2 , and 3 was $53(52.5 \%), 37(36.5 \%)$, and $1(1.0 \%)$ respectively.

Table 4 shows the distribution of pneumoconiosis cases in the three villages according to size and shape of small opacities. In most cases of simple pneumoconiosis, the $p$ type and the $q$ type of small

Table 4 Distribution of pneumoconiosis cases according to size and shape of small opacities (ILO 1980) in three villages of Ladakh

\begin{tabular}{llll}
\hline & \multicolumn{1}{l}{ Village } \\
\cline { 2 - 4 } Size and shape & $A(n=150)$ & $B(n=149)$ & $C(n=150)$ \\
\hline $\mathrm{p}$ & $1(0 \cdot 7)$ & $11(7 \cdot 4)$ & $39(26 \cdot 0)$ \\
$\mathrm{q}$ & $2(1 \cdot 3)$ & $13(8 \cdot 7)$ & $21(14 \cdot 0)$ \\
$\mathrm{r}$ & - & $2(1 \cdot 3)$ & $1(0 \cdot 7)$ \\
$\mathrm{s}$ & - & $4(2 \cdot 7)$ & $5(3 \cdot 3)$ \\
$\mathrm{t}$ & - & $1(0 \cdot 7)$ & $2(1 \cdot 3)$ \\
$\mathrm{u}$ & - & - & - \\
\hline
\end{tabular}

Figures in parentheses are percentages. 


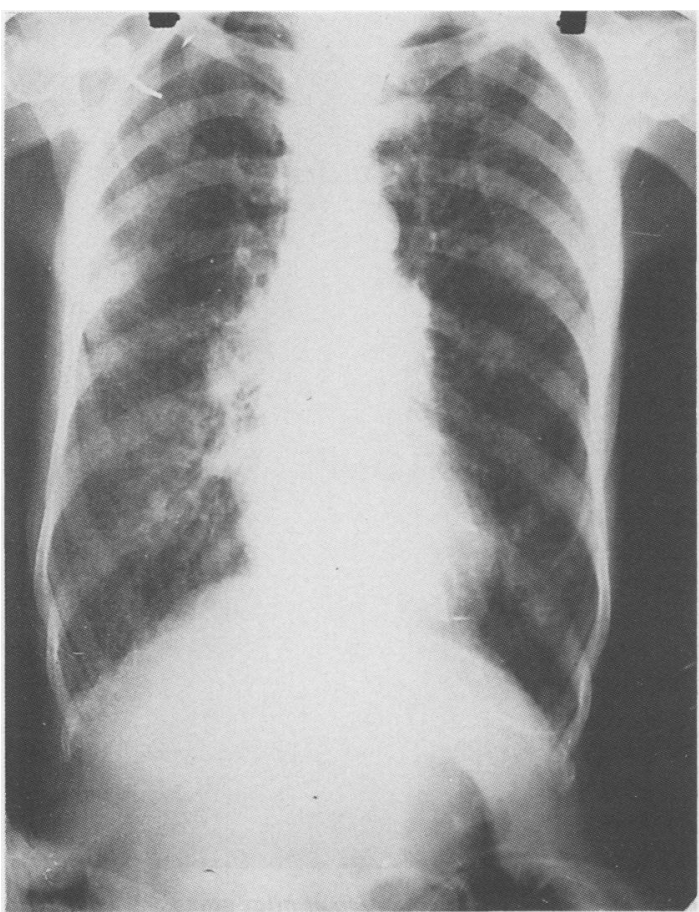

Figure 1 Woman aged 65 with cough, sputum production, progressive dyspnoea, bilateral basal crepitus, and clubbing of fingers. The clinical picture resembled diffuse interstitial pulmonary fibrosis.

opacities were found. In 12 subjects (six each from villages $B$ and $C$ ), the predominant small opacities were irregular in type, and were found in the middle and lower zones of both lung fields (fig 1). In these subjects dyspnoea was the major complaint and clubbing of the fingers was found in four. The clinical picture in these cases resembled diffuse interstitial pulmonary fibrosis.

Table 5 shows the profusion distribution of cases of pneumoconiosis in the three villages. The prevalence of pneumoconiosis in villages $\mathrm{A}, \mathrm{B}$, and $\mathrm{C}$ was $2 \cdot 0 \%, 20 \cdot 1 \%$, and $45.3 \%$ respectively. The prevalence of all categories of pneumoconiosis was

Table 5 Distribution of pneumoconiosis (ILO 1980) cases in villages of Ladakh

\begin{tabular}{llll}
\hline & \multicolumn{3}{l}{ Village } \\
\cline { 2 - 4 } No & $A(n=150)$ & $B(n=149)$ & $C(n=150)$ \\
\hline Total cases & $3(2 \cdot 0)$ & $31(20 \cdot 1)$ & $68(45 \cdot 3)$ \\
Category 1 & $1(0 \cdot 7)$ & $16(10 \cdot 7)$ & $36(24 \cdot 0)$ \\
Category 2 & $2(1 \cdot 3)$ & $15(10 \cdot 1)$ & $31(20 \cdot 7)$ \\
Category 3 & - & - & $1(0 \cdot 7)$ \\
Category A & - & - & $1(0 \cdot 7)$ \\
Category B & - & - & $4(2 \cdot 7)$ \\
Category C & - & - & $4(2 \cdot 7)$ \\
\hline
\end{tabular}

Figures in parentheses are percentages. highest in village $C$. In all villages, most of the cases of pneumoconiosis belonged to category 1 and category 2 . The cases with large opacities (categories $\mathrm{A}, \mathrm{B}$, and $\mathrm{C}$ ) were found mainly in village $\mathrm{C}$. These resembled complicated pneumoconiosis as found after exposure to free silica, which is sometimes distinguished by the presence of egg shell calcification of hilar glands (fig 2) or those found in progressive massive fibrosis of coal workers' pneumoconiosis (fig 3). All these cases of large opacities (except one) were from village $C$ where the dust storms are severe and chimneys are mostly not used in the houses. Egg shell calcification of hilar glands was found in 12 subjects; 11 of these subjects were from village $C$ and the remaining subject was from village $B$. In one, egg shell calcification of hilar glands was found with no evidence of pneumoconiosis in the lung fields (fig 4).

Table 6 shows the distribution of the cases of pneumoconiosis by age and sex. The prevalence of pneumoconiosis increased with age but differences due to sex were not significant.

Table 7 shows the mean indoor dust concentrations during the cooking hours. The same fireplace and fuels are used for heating and cooking in most of the houses. The kitchen is usually also used as a bedroom. The dust concentrations in villages $\mathrm{A}, \mathrm{B}$, and $C$ were $0.51,0.87$, and $7.50 \mathrm{mg} / \mathrm{m}^{3}$ respectively.

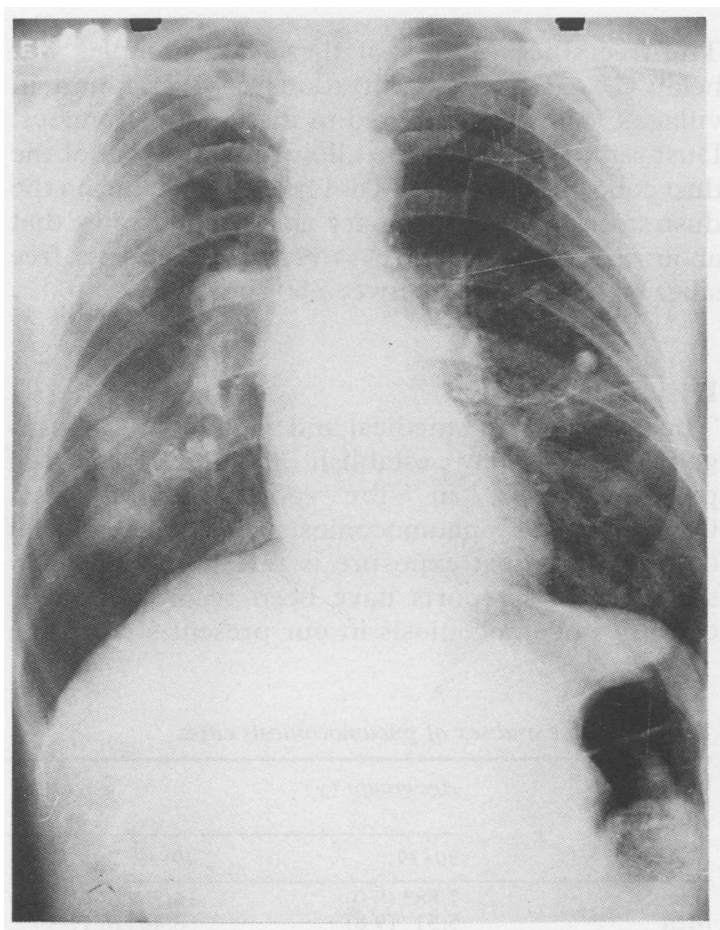

Figure 2 Progressive massive fibrosis with egg shell calcification of hilar glands. 


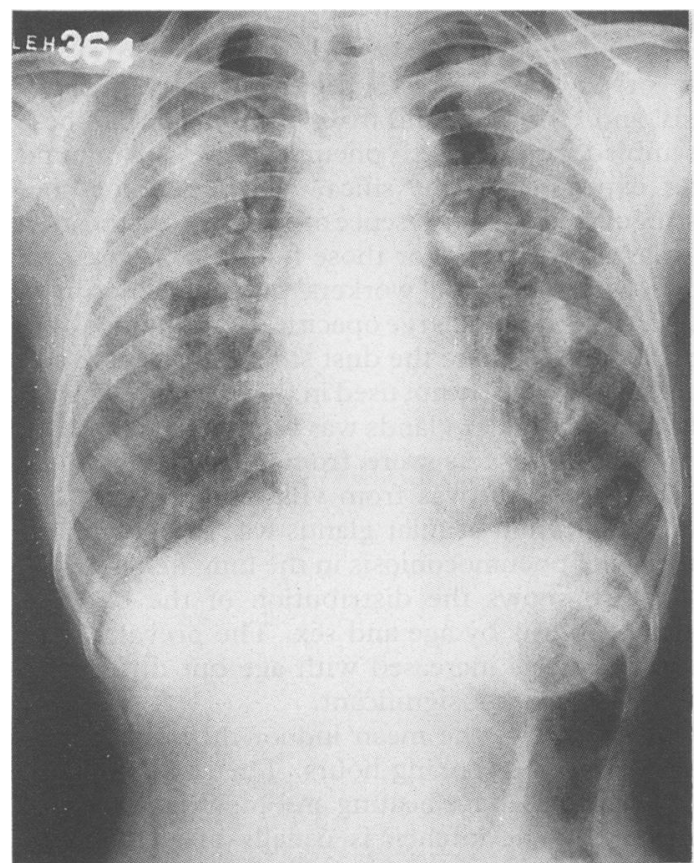

Figure 3 Pneumoconiosis resembling progressive massive fibrosis found in coal workers' pneumoconiosis.

The free silica content of these dust samples was below $1 \%$. High concentrations of dust found in village $\mathrm{C}$ may be attributed to the lack of chimneys. Dust samples sufficient to allow measurement of the dust concentrations could not be collected during the dust storms but preliminary analysis indicates that about $80 \%$ of the dust was respirable and its free silica content ranged between 60 and $70 \%$.

\section{Discussion}

The results of our medical and radiological investigations positively establish the occurrence of pneumoconiosis in the population studied. Occurrence of pneumoconiosis in the absence of occupational dust exposure is rare and only a few scattered case reports have been recorded. ${ }^{4-6}$ The cases of pneumoconiosis in our present study were

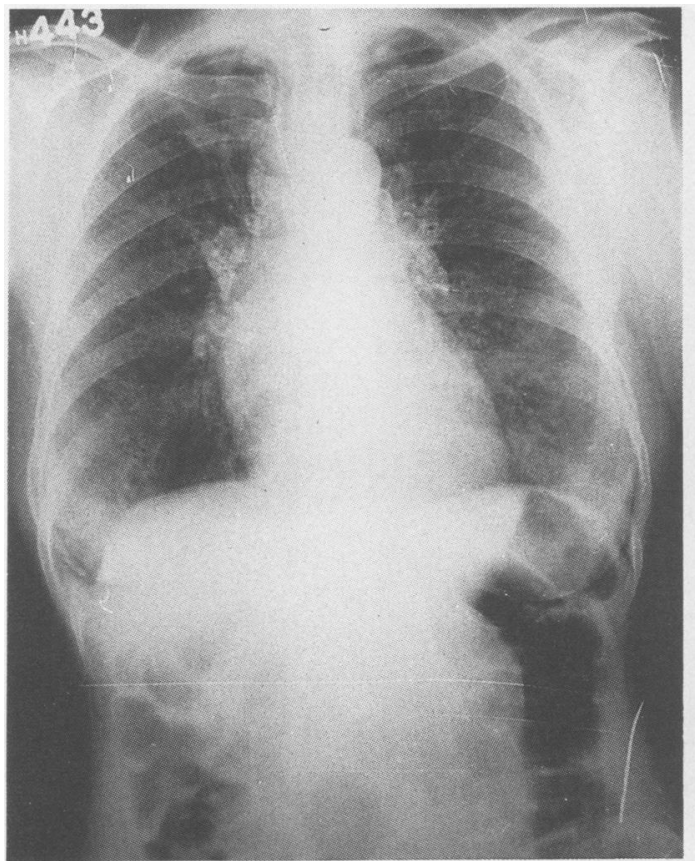

Figure 4 Egg shell calcification of hilar glands without evidence of pneumoconiosis in the lung fields.

found mainly in village $B$ and village $C$, where the dust storms are frequent during summer. Maximum prevalence of pneumoconiosis in village $\mathrm{C}$ can be attributed to the inhalation of fine dust during the storms and the soot arising from the fuels used for cooking and heating purposes. Excessive generation of soot may result from incomplete burning of fuels due to lack of oxygen at high altitude. The free silica has a toxic action on macrophages, ${ }^{7}$ which may result in the accumulation of inert dust such as soot. Therefore, simultaneous exposure to free silica and soot in these villagers might have resulted in accumulation of soot in the lungs.

The radiological picture highlighting the presence of egg shell calcification of the hilar glands indicates exposure to high concentrations of free silica dust that, under the prevailing conditions, could be attributed only to the dust storms. The source of

Table 6 Age and sex of pneumoconiosis cases

Age groups ( $y$ )

\begin{tabular}{|c|c|c|c|c|c|}
\hline Sex & $30-39$ & $40-49$ & $50-59$ & $\geqslant 60$ & Total \\
\hline $\begin{array}{l}\text { Women } \\
\text { Men }\end{array}$ & $\begin{array}{l}7 / 88^{\star}(8 \cdot 0) \\
5 / 51 \quad(9 \cdot 8)\end{array}$ & $\begin{array}{r}15 / 53(28 \cdot 3) \\
8 / 48(16 \cdot 7)\end{array}$ & $\begin{array}{l}17 / 72(23.6) \\
11 / 38(28.9)\end{array}$ & $\begin{array}{l}13 / 33(39 \cdot 4) \\
25 / 66(37 \cdot 9)\end{array}$ & $\begin{array}{l}52 / 246(21 \cdot 1) \\
49 / 203(24 \cdot 1)\end{array}$ \\
\hline
\end{tabular}

^No of cases/subjects in the age group.

Figures in parentheses are percentages. 
Table 7 Indoor respirable dust concentrations (mean (range)) during cooking periods in different villages

\begin{tabular}{ll}
\hline Village & Dust concentrations indoors $\left(\mathrm{mg} / \mathrm{m}^{3}\right)$ \\
\hline A (with chimney) & $0.509(0 \cdot 200-0.966)$ \\
B (with chimney) & $0.861(0.563-1 \cdot 467)$ \\
C (without chimney) & $7.495(3.222-11 \cdot 300)$ \\
\hline
\end{tabular}

these storms and their composition remains to be studied.

In this community based survey a large proportion of a randomly selected population was found to be suffering from pneumoconiosis with no possibility of occupational exposure to dust from mines or surface industry. The discovery of pneumoconiosis in these remotely situated villages is interesting from an academic and an applied point of view. A need exists for an in depth study of the source, concentration, and composition of the causative dust, and the natural history of the disease.

We thank Dr Stanzin Tundup, Superintendent, SNM Hospital Leh, and his staff for their help during the study. We are grateful to Professor S R Kamath, KEM Hospital, Bombay, for reading the radiographs. We acknowledge $\mathrm{Mr} \mathrm{A} \mathrm{K}$ Dey for patiently typing the manuscript.

Requests for reprints to: Dr H N Saiyed, Regional Occupational Health Centre (Eastern), 3 Dr M Ishaque Road (Kyd Street), Calcutta-700016, India.

1 International Labour Organisation. Guidelines for the use of the ILO international classification of the radiographs of pneumoconiosis. Geneva: ILO, 1980. (Occupational safety and health series No 22.)

2 Sweet DV, Wolowicz FR, Crable JV. Spectrophotometric determination of free silica. Am Ind Hyg Assoc J 1973;34: $500-6$.

3 Morgan WKC. Coal workers' pneumoconiosis, In: Morgan WKC, Seaton A, eds. Occupational lung diseases. Philadelphia: W B Saunders, 1984:377-448.

4 Goyal RK. Pneumoconiosis in industrial population of Rajasthan. J Indian Med Assoc 1958;30:79-82.

5 Sepke G. Silicosis from street dust. Z Gesamte Hyg 1961;7: 833-7.

6 Farina G, Gambini G. A rare case of silicosis from inhalation of desert sand. Med Lav 1968;59:281-6.

7 Allison AC, Harrington JS, Birbeck $M$. An examination of cytotoxic effects of silica on macrophages. $J$ Exp Med 1966;124:141-54.

Accepted 4 March 1991

\section{Correspondence and editorials}

The British Journal of Industrial Medicine welcomes correspondence relating to any of the material appearing in the journal. Results from preliminary or small scale studies may also be published in the correspondence column if this seems appropriate. Letters should be not more than $\mathbf{5 0 0}$ words in length and contain a minimum of references. Table and figures should be kept to an absolute minimum. Letters are accepted on the understanding that they may be subject to editorial revision and shortening.

The journal now also publishes editorials which are normally specially commissioned. The Editor welcomes suggestions regarding suitable topics; those wishing to submit an editorial, however, should do so only after discussion with the Editor. 